\title{
Um Estudo Exploratório sobre a Satisfação do Usuário de Sistemas de Software
}

\author{
Tereza G. Kirner; José Carlos Perini; Maria I. Montebelo \\ Universidade Metodista da Piracicaba \\ Programa de Pós-Graduação em Ciência da Computação \\ Rodovia do Açúcar, Km 156 - 13400-911, Piracicaba - SP \\ \{tgkirner, milmonte\}@unimep.br, jcperini@uol.com.br
}

\begin{abstract}
This work focuses on the user satisfaction of software products, proposing a model to evaluate the user satisfaction and discussing a research, based on the proposed model, which evaluated the user satisfaction of a software applied to the educational management area. The model is presented and the planning, implementation, data analysis and results of the research are discussed. The work aims at contributing to the evaluation of user satisfaction as well as to the quality improvement of software products.
\end{abstract}

Resumo. Este trabalho trata da satisfação do usuário de produtos de software, apresentando um modelo para avaliar a satisfação do usuário e discutindo uma pesquisa, realizada, com base no modelo proposto, junto a usuários de um software de gestão acadêmica. $O$ planejamento, implementação, análise de dados e resultados da pesquisa são apresentados. O trabalho visa contribuir para a avaliação da satisfação do usuário e para a melhoria da qualidade de sistemas de software.

\section{Introdução}

O sucesso da implantação e uso de sistemas de software nas organizações depende não apenas do atendimento de características essencialmente técnicas, assumidas durante o processo de desenvolvimento, mas também da priorização de aspectos que, incorporados ao produto, levem à sua adequada utilização. Esses aspectos estão normalmente relacionados à usabilidade do software, que é um requisito de qualidade que envolve aspectos específicos, entre os quais se destaca a satisfação do usuário.

A satisfação do usuário é, portanto, um atributo de qualidade que contribui para a usabilidade dos produtos de software [Abran, 2003; Sommerville, 2007]. Essa satisfação é determinada tanto por características relacionadas a medidas internas do software, como segurança e confiabilidade, por exemplo, quanto por característica subjetivas, de ordem externa, relacionadas às necessidades e expectativas do usuário. Os usuários incluem os indivíduos que interagem com determinado sistema ou aplicação de software.

Este trabalho tem dois objetivos principais: (a) propor um Modelo de Avaliação da Satisfação do Usuário; e (b) discutir um estudo empírico exploratório, realizado junto a usuários de um Sistema de Gestão Acadêmica, baseado no Modelo proposto. Com 
esses objetivos, pretende-se contribuir para a pesquisa e a prática relativa ao atendimento de requisitos ligados à satisfação dos usuários.

A seção 2 destaca trabalhos relacionados ao tema, que forneceram uma base conceitual para o presente trabalho. A seção 3 detalha o modelo de satisfação do usuário proposto. A seção 4 apresenta o estudo empírico realizado junto a usuários de um sistema, utilizando o modelo definido. A seção 5 descreve a análise de dados realizada e os principais resultados obtidos. As conclusões do trabalho são apresentadas na seção 6 .

\section{Trabalhos Relacionados}

Para se obter sistemas de software compatíveis com o que os usuários necessitam e esperam, é fundamental se investir em modelos de avaliação de software direcionados especificamente para medir o nível de satisfação expressado pelos usuários para com os sistemas que eles utilizam ou estão em vias de utilizar.

DeLone e McLean $(1992,2002,2003)$ propuseram um modelo para avaliação da qualidade de sistemas, bastante divulgado e empregado em pesquisas sobre avaliação de aplicações e produtos de software. Segundo esse modelo, o sucesso de um sistema é resultado da combinação de quatro fatores chaves, que, juntos, podem gerar um impacto individual e um impacto organizacional positivo, resultando no sucesso do sistema: a qualidade do sistema, a qualidade da informação, o uso do sistema e a satisfação do usuário. A satisfação do usuário é um componente de destaque desse modelo, definido a partir de características ligadas ao uso do sistema, ao acesso às funções e resultados do sistema e também a características pessoais e subjetivas relacionadas às necessidades e expectativas do usuário.

Tratando especificamente da avaliação da satisfação do usuário, destaca-se o modelo EUCS - End-User Computing Satisfaction [Doll, 2000; Ives, 1993]. Esse modelo enfoca dimensões distintas da satisfação do usuário, tais como: conteúdo do sistema, acurácia das informações geradas, formato de apresentação das informações pelo sistema, facilidade de uso do sistema e fornecimento de informações em tempo adequado para a execução das tarefas e tomada de decisões por parte dos usuários.

Tanto as pesquisas que utilizaram o Modelo DeLone [Iivari, 2005; DeLone, 2003] quanto as que aplicaram o Modelo EUCS [Abdnnour, 2005; Barner, 2006; Chin, 2000; Zviran, 2006] forneceram um referencial teórico importante para a realização de estudos sobre satisfação do usuário de sistemas de software. No entanto, ambos apresentam deficiências, que se procurou sanar no presente trabalho. O Modelo DeLone não trata extensivamente dos aspectos específicos da satisfação do usuário e enfatiza muito o processo de análise estatística dos dados, em detrimento do detalhamento dos quesitos e características de qualidade. O Modelo EUCS, por sua vez, é muito detalhista, propondo um conjunto muito grande de questões, com aspectos repetitivos, que dificulta o levantamento de dados junto aos usuários. No estudo aqui apresentado buscou-se um avanço em relação aos trabalhos existentes, objetivando-se, principalmente, definir um Modelo de Satisfação do Usuário simples, claro e possível de ser aplicado na avaliação de sistemas reais e envolvendo usuários reais. 


\section{Modelo de Satisfação do Usuário}

Para a realização do estudo empírico, foi proposto um modelo composto por um conjunto de dez quesitos que retratam a satisfação do usuário, cada um deles avaliados através de duas questões. Para se chegar a esses quesitos, foram considerados os trabalhos existentes relacionados ao tema, principalmente os que apresentam o Modelo DeLone \& McLean e o Modelo EUCS, citados na seção anterior. Os quesitos constantes desses dois modelos foram analisados e discutidos, chegando-se, assim, aos dez quesitos aqui considerados.

O Quadro 1 define os quesitos que compõem a satisfação do usuário.

Quadro 1. Quesitos que compõem a satisfação do usuário

\begin{tabular}{|l|l|}
\hline Quesito & Descrição \\
\hline Conteúdo do sistema & $\begin{array}{l}\text { Envolve o conteúdo das informações fornecidas pelo sistema, se estas } \\
\text { informações são suficientes e se atendem às necessidades do usuário. }\end{array}$ \\
\hline Exatidão & Refere-se à confiabilidade do sistema e se a informação é exata. \\
\hline Segurança & Indica se a informação é segura. \\
\hline Formato & $\begin{array}{l}\text { Diz respeito ao formato em que os resultados são apresentados ao } \\
\text { usuário. }\end{array}$ \\
\hline Facilidade de uso & $\begin{array}{l}\text { Refere-se à facilidade que o usuário tem para operar o sistema e obter } \\
\text { o resultado desejado. }\end{array}$ \\
\hline Pontualidade da informação & $\begin{array}{l}\text { Indica se a informação é obtida pelo usuário no momento que precisa } \\
\text { dela e se essa informação é atualizada. }\end{array}$ \\
\hline Velocidade do sistema & Refere-se ao tempo que o usuário leva para obter as informações. \\
\hline Flexibilidade & $\begin{array}{l}\text { Refere-se à possibilidade que o usuário tem de configurar ou definir o } \\
\text { sistema ou parte dele. }\end{array}$ \\
\hline Atratividade & $\begin{array}{l}\text { Refere-se às características atrativas do sistema, entre elas o aspecto } \\
\text { visual. }\end{array}$ \\
\hline Satisfação geral & $\begin{array}{l}\text { Diz respeito à satisfação do usuário na utilização do sistema, de uma } \\
\text { maneira geral. }\end{array}$ \\
\hline
\end{tabular}

O Quadro 2 apresenta as questões referentes a cada quesito considerado, além de uma questão final que solicita comentários de ordem geral.

Quadro 2. Questões relacionadas aos quesitos da satisfação do usuário

\begin{tabular}{|c|}
\hline Questões por Qu \\
\hline $\begin{array}{l}\text { Conteúdo do sistema } \\
\text { Q1. O conteúdo da informação vem ao encontro do que você necessita? Por exemplo, quando você } \\
\text { solicita um relatório, o resultado é o que você realmente precisa? } \\
\text { Q2. O sistema fornece informações completas e suficientes? Por exemplo, quando você solicita um } \\
\text { relatório, o resultado é completo e suficiente? }\end{array}$ \\
\hline $\begin{array}{l}\text { Exatidão } \\
\text { Q3. A seu ver, o sistema fornece informações confiáveis? Por exemplo, para solicitações iguais, o } \\
\text { sistema fornece resultados iguais? } \\
\text { Q4. O sistema fornece informação exata? Por exemplo, o relatório de Turmas em Andamento apresenta } \\
\text { as informações corretas e organizadas de forma adequada? }\end{array}$ \\
\hline $\begin{array}{l}\text { Segurança } \\
\text { Q5. A seu ver, o sistema é seguro? Por exemplo, o usuário pode utilizar senhas de acesso ao sistema? } \\
\text { Q6. O sistema tem facilidade de recuperar erros? Por exemplo, se ocorrer um erro no sistema, os dados } \\
\text { são recuperados com facilidade? }\end{array}$ \\
\hline $\begin{array}{l}\text { Formato } \\
\text { Q7. Você acha que o resultado é apresentado em um formato útil? Por exemplo, os relatórios, tabelas e } \\
\text { listagens são mostrados de forma a destacar as informações importantes? } \\
\text { Q8. A informação é clara? Por exemplo, você consegue visualizar rapidamente e facilmente a }\end{array}$ \\
\hline
\end{tabular}




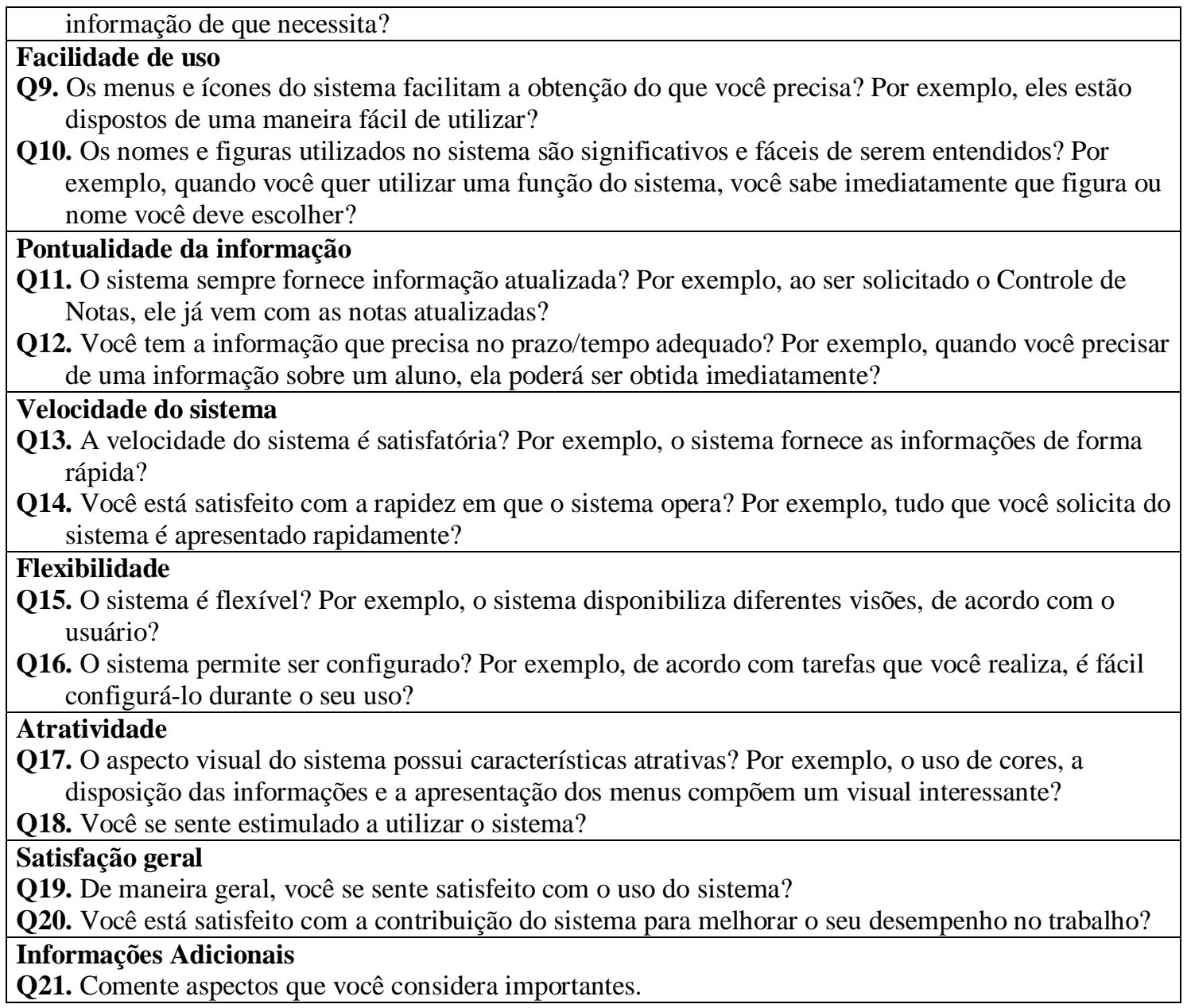

Para avaliação dos quesitos, foram utilizadas métricas definidas por meio de uma escala de Likert de cinco pontos [Pereira, 2006], associada a cada questão listada no Quadro 2. A escala de Likert permite que os usuários informem qual o grau de concordância ou discordância com uma questão ou afirmativa apresentada, utilizando valores associados a métricas qualitativas previamente definidas. O Quadro 3 ilustra a escala adotada no estudo.

Quadro 3. Escala de Likert utilizada no estudo

\begin{tabular}{|l|c|c|c|c|c|}
\hline métricas & $\begin{array}{c}\text { nunca ou } \\
\text { quase nunca }\end{array}$ & $\begin{array}{c}\text { algumas } \\
\text { vezes }\end{array}$ & $\begin{array}{c}\text { metade } \\
\text { das vezes }\end{array}$ & $\begin{array}{c}\text { muitas } \\
\text { vezes }\end{array}$ & $\begin{array}{c}\text { sempre ou } \\
\text { quase sempre }\end{array}$ \\
\hline valores & 1 & 2 & 3 & 4 & 5 \\
\hline
\end{tabular}

\section{Definição e Realização do Estudo Empírico}

O estudo empírico foi organizado em etapas, de acordo com diretrizes propostas em Travassos (2002) e Wohlin (2000). O estudo teve como objetivo avaliar a satisfação do usuário do software SGA (Sistema de Gestão Acadêmica), um software de gestão escolar utilizado por uma Escola de Computação que ministra cursos de extensão e treinamento em informática, que possui várias franquias no estado de São Paulo. A avaliação da satisfação do usuário enfocou o módulo do software destinado às 
coordenações e secretarias dos cursos, tomando por base o modelo apresentado na seção anterior.

O SGA é usado por 40 unidades da Escola no estado de São Paulo, entre as quais foram escolhidas sete unidades da região de Campinas para participarem da pesquisa. Utilizou-se, portanto, uma amostra por conveniência [Levine, 2005], definida com base em facilidade para o pesquisador. Essa amostra constituiu-se dos 32 funcionários das sete unidades da Escola, que são usuários do sistema.

Como usuários, foram considerados os funcionários das unidades da escola que utilizam o sistema SGA para desempenhar as tarefas da secretaria e da coordenação de cursos, incluindo controle de alunos, de turmas e de cursos ministrados pelas unidades.

A coleta de dados foi feita por meio de três instrumentos:

- Questionário de Avaliação do Perfil do Usuário. Este questionário refere-se a informações gerais do perfil dos usuários que participaram do estudo, constando de seis perguntas de múltipla escolha.

- Formulário de Descrição das Tarefas. Este formulário compreende um conjunto de tarefas baseadas nas funções exigidas para a condução das atividades de secretaria e coordenação dos cursos na Escola, passíveis de serem apoiadas pelo SGA. Os usuários foram solicitados a exercitar essas tarefas, utilizando o sistema, antes de responderem o Questionário de Avaliação da Satisfação do Usuário.

- Questionário de Avaliação da Satisfação do Usuário. Este questionário é composto de 21 questões, sendo vinte questões a serem respondidas de acordo com a escala de Likert adotada e uma questão aberta (ver Quadro 2). Os participantes da avaliação deveriam responder cada questão, assinalando um dos valores apresentados na escala adotada.

Tendo em vista o caráter exploratório do estudo, optou-se por definir duas perguntas básicas para a pesquisa, sem a formulação de hipótese, o que é um procedimento aceito para a condução de pesquisas [Pereira, 2004].

A pesquisa buscou responder às seguintes perguntas:

Pergunta 1: Qual o nível de satisfação do usuário com o sistema, relacionado com cada um dos quesitos propostos, ou seja: conteúdo do sistema, exatidão, segurança, formato, facilidade de uso, pontualidade da informação, velocidade do sistema, flexibilidade, atratividade e satisfação geral?

Para responder essa pergunta, foram analisadas as respostas dadas às questões constantes no Questionário de Avaliação da Satisfação do Usuário. Para determinar o nível de satisfação do usuário, enfocando cada quesito, foram assumidos os seguintes parâmetros: 
- Um resultado incluindo entre $50 \%$ e $75 \%$ de respostas 4 (muitas vezes) e 5 (sempre ou quase sempre), em conjunto, indicaria que os usuários estavam satisfeitos com o sistema, sob o ponto de vista do quesito considerado.

- Um resultado incluindo entre $76 \%$ e $100 \%$ de respostas 4 (muitas vezes) e 5 (sempre ou quase sempre), em conjunto, indicaria que os usuários estavam muito satisfeitos com o sistema, sob o ponto de vista do quesito considerado.

- Um resultado incluindo entre $50 \%$ e $75 \%$ de respostas 1 (nunca ou quase nunca), 2 (algumas vezes) e 3 (metade das vezes), somadas, indicaria que os usuários estavam insatisfeitos com o sistema, sob o ponto de vista do quesito considerado.

- Um resultado incluindo entre $76 \%$ e $100 \%$ de respostas 1 (nunca ou quase nunca), 2 (algumas vezes) e 3 (metade das vezes), somadas, indicaria que os usuários estavam muito insatisfeitos com o sistema, sob o ponto de vista do quesito considerado.

Pergunta 2: Existe diferença entre o nível de satisfação com o sistema, expressado por diferentes categorias de usuários, considerando-se, nestas categorias, o tipo de atividade exercida e o tempo de experiência com o uso do sistema?

Para responder essa pergunta, as respostas às questões constantes no Questionário de Avaliação da Satisfação do Usuário foram comparadas com os seguintes dados obtidos pelo Questionário de Avaliação do Perfil do Usuário: (a) tipo de atividade exercida pelo usuário, se atividade de secretaria ou atividade de coordenação; e (b) tempo de experiência do usuário com o sistema, se até 1 ano de experiência ou mais de 1 ano de experiência.

Para identificar se existe diferença no nível de satisfação com o sistema, entre as diferentes categorias de usuários, foi aplicado o Teste Mann-Whitney [Pereira, 2004], considerando-se um nível de significância de $0,05^{(\mathbf{1})}$. parâmetros:

A avaliação dos resultados obtidos foi realizada com base nos seguintes

- Se o valor $p$, obtido no teste Mann-Whitney, for igual ou maior que 0,05 , será considerado que não existe diferença significativa entre os níveis de satisfação do usuário em relação ao sistema, expressados pelas categorias consideradas.

- Se o valor $p$, obtido no teste Mann-Whitney, for menor que 0,05, será considerado que existe diferença significativa entre os níveis de satisfação do usuário em relação ao sistema, expressados pelas categorias consideradas. estudo:

Os seguintes cuidados foram tomados visando para garantir a validade do

(1) O Teste Mann-Whitney é indicado para verificar se duas amostras pertencem ou não à mesma população ou se, em uma amostra aleatória, subdividida em grupos, existe uma diferença muito grande nas respostas provenientes dos diferentes grupos [Levine, 2005; Pereira, 2004]. 
- Realizar um teste piloto, com a colaboração de um usuário do sistema, a fim de verificar a compreensão do usuário em relação aos questionários. Ao realizar o teste, o usuário foi orientado a identificar questões ambíguas, não claras e confusas, o que possibilitou a realização de correções e complementações nos instrumentos de pesquisa.

- Enviar uma carta, entregue em mãos aos diretores das unidades participantes, explicando a importância da pesquisa para a melhoria da qualidade do software e, conseqüentemente, da produtividade dos funcionários nas suas atividades e decisões do dia-a dia da escola.

- Fazer uma reunião inicial com os participantes, explicando os detalhes da pesquisa e esclarecendo possíveis dúvidas.

A coleta de dados foi executada nos meses de outubro e novembro de 2007, em datas agendadas com os diretores das respectivas unidades da escola. Os 32 usuários que compõem a amostra responderam os questionários.

\section{Análise dos Dados e Resultados}

\subsection{Aspectos Gerais}

A análise dos dados embasou-se em fundamentos e técnicas da estatística [Levine, 2005; Pereira, 2004]. Os dados, coletados através dos questionários, foram processados através do software SPSS 10.1 [SPSS, 2007], sendo obtidas as frequiências de respostas às questões e preparados quadros e tabelas que elucidam os resultados. A discussão completa dos dados coletados, técnicas aplicadas e resultados obtidos é discutida em Perini (2008).

A Tabela 1 contém as freqüências das respostas fornecidas pelos usuários às questões constantes do Questionário de Avaliação da Satisfação do Usuário. Para cada questão (Q1 a Q20), relacionada aos 10 quesitos que compõem o Modelo de Satisfação do Usuário, são mostradas a quantidade e a porcentagem de respostas obtidas, agrupadas com base nas métricas da escala de Likert adotada.

Consultando-se a Tabela 1, verifica-se que:

- A maior freqüência de resposta, apontada por 23 usuários, foi a resposta 5, relativa à métrica "sempre ou quase sempre" da questão Q5. Conforme mostra o Quadro 1, a questão 5 refere-se ao quesito Segurança, que verifica se o usuário considera o sistema seguro. A freqüência obtida nesta questão indicou que $72 \%$ dos usuários mostraram-se satisfeitos quanto ao aspecto de segurança do Sistema SGA. 
Tabela 1. Freqüência das respostas

\begin{tabular}{|c|c|c|c|c|c|c|c|c|c|c|c|}
\hline \multirow{4}{*}{$\begin{array}{c}\text { Quesitos } \\
\text { Conteúdo do } \\
\text { sistema }\end{array}$} & \multirow{3}{*}{$\begin{array}{c}\text { Questões } \\
\text { Q1 }\end{array}$} & \multicolumn{10}{|c|}{ Categorias (escala de Likert) } \\
\hline & & \multicolumn{2}{|c|}{$\begin{array}{c}\text { (1) } \\
\text { Nunca ou } \\
\text { quase nunca }\end{array}$} & \multicolumn{2}{|c|}{$\begin{array}{c}(2) \\
\text { Algumas } \\
\text { vezes }\end{array}$} & \multicolumn{2}{|c|}{$\begin{array}{c}\text { (3) } \\
\text { Metade das } \\
\text { vezes }\end{array}$} & \multicolumn{2}{|c|}{$\begin{array}{c}\text { (4) } \\
\text { Muitas } \\
\text { vezes }\end{array}$} & \multicolumn{2}{|c|}{$\begin{array}{c}(5) \\
\text { Sempre ou } \\
\text { quase sempre }\end{array}$} \\
\hline & & 0 & $0 \%$ & 1 & $3 \%$ & 3 & $9 \%$ & 16 & $50 \%$ & 12 & $38 \%$ \\
\hline & Q2 & 0 & $0 \%$ & 3 & $9 \%$ & 2 & $6 \%$ & 15 & $47 \%$ & 12 & $38 \%$ \\
\hline \multirow{2}{*}{ Exatidão } & Q3 & 0 & $0 \%$ & 0 & $0 \%$ & 3 & $9 \%$ & 13 & $41 \%$ & 16 & $50 \%$ \\
\hline & Q4 & 1 & $3 \%$ & 3 & $9 \%$ & 2 & $6 \%$ & 12 & $38 \%$ & 14 & $44 \%$ \\
\hline \multirow{2}{*}{ Segurança } & Q5 & 2 & $6 \%$ & 1 & $3 \%$ & 1 & $3 \%$ & 5 & $16 \%$ & 23 & $72 \%$ \\
\hline & Q6 & 2 & $6 \%$ & 4 & $13 \%$ & 5 & $16 \%$ & 14 & $44 \%$ & 7 & $22 \%$ \\
\hline \multirow{2}{*}{ Formato } & Q7 & 0 & $0 \%$ & 1 & $3 \%$ & 3 & $9 \%$ & 17 & $53 \%$ & 11 & $34 \%$ \\
\hline & Q8 & 0 & $0 \%$ & 1 & $3 \%$ & 5 & $16 \%$ & 15 & $47 \%$ & 11 & $34 \%$ \\
\hline \multirow{2}{*}{$\begin{array}{c}\text { Facilidade de } \\
\text { uso }\end{array}$} & Q9 & 0 & $0 \%$ & 1 & $3 \%$ & 5 & $16 \%$ & 14 & $44 \%$ & 12 & $38 \%$ \\
\hline & Q10 & 0 & $0 \%$ & 2 & $6 \%$ & 3 & $9 \%$ & 12 & $38 \%$ & 15 & $47 \%$ \\
\hline \multirow{2}{*}{$\begin{array}{c}\text { Pontualidade } \\
\text { da informação }\end{array}$} & Q11 & 0 & $0 \%$ & 1 & $3 \%$ & 3 & $9 \%$ & 16 & $50 \%$ & 12 & $38 \%$ \\
\hline & Q12 & 0 & $0 \%$ & 1 & $3 \%$ & 3 & $9 \%$ & 15 & $47 \%$ & 13 & $41 \%$ \\
\hline \multirow{2}{*}{$\begin{array}{c}\text { Velocidade do } \\
\text { sistema }\end{array}$} & Q13 & 0 & $0 \%$ & 2 & $6 \%$ & 4 & $13 \%$ & 16 & $50 \%$ & 10 & $31 \%$ \\
\hline & Q14 & 0 & $0 \%$ & 4 & $13 \%$ & 9 & $28 \%$ & 12 & $38 \%$ & 7 & $22 \%$ \\
\hline \multirow{2}{*}{ Flexibilidade } & Q15 & 4 & $13 \%$ & 5 & $16 \%$ & 5 & $16 \%$ & 9 & $28 \%$ & 9 & $28 \%$ \\
\hline & Q16 & 5 & $16 \%$ & 7 & $22 \%$ & 6 & $19 \%$ & 8 & $25 \%$ & 6 & $19 \%$ \\
\hline \multirow{2}{*}{ Atratividade } & Q17 & 9 & $28 \%$ & 4 & $13 \%$ & 5 & $16 \%$ & 8 & $25 \%$ & 6 & $19 \%$ \\
\hline & Q18 & 0 & $0 \%$ & 5 & $16 \%$ & 2 & $6 \%$ & 13 & $41 \%$ & 12 & $38 \%$ \\
\hline \multirow{2}{*}{ Satisfação geral } & Q19 & 0 & $0 \%$ & 2 & $6 \%$ & 2 & $6 \%$ & 15 & $47 \%$ & 13 & $41 \%$ \\
\hline & Q20 & 0 & $0 \%$ & 1 & $3 \%$ & 2 & $6 \%$ & 14 & $44 \%$ & 15 & $47 \%$ \\
\hline
\end{tabular}

Figura 1. Gráfico de freqüiências das respostas às questões

- A questão que obteve a maior freqüência de respostas 1 (relativa à métrica "nunca ou quase nunca") foi a questão Q17, com 9 respostas. Essa questão refere-se ao quesito Atratividade, abordando especificamente o aspecto visual do sistema, conforme mostra o Quadro 2. A freqüência obtida nesta questão indicou que $28 \%$ dos usuários não consideram o sistema visualmente atrativo, o que contribuiu para o nível deficiente de satisfação do usuário quanto à atratividade do Sistema SGA.

- A questão que obteve a maior freqüência de respostas 2 (relativa à métrica "algumas vezes") foi a questão Q16, com 7 respostas. Essa questão refere-se ao quesito Flexibilidade, perguntando especificamente se o sistema permite ser configurado pelo usuário. A freqüência obtida nesta questão indicou que $22 \%$ dos usuários afirmaram que o sistema permite ser configurado apenas algumas vezes, o que contribuiu para o nível deficiente de satisfação do usuário quanto à flexibilidade do Sistema SGA.

- A questão que obteve a maior freqüência de resposta 3 (relativa à métrica "metade das vezes") foi a questão Q14, com 9 respostas. Essa questão refere-se ao quesito Velocidade do Sistema, perguntando especificamente se o usuário está satisfeito com a rapidez em que o sistema opera. A freqüência obtida nesta questão indica que $28 \%$ dos usuários manifestaram que metade das vezes estão satisfeitos e metade das vezes estão insatisfeitos com esse quesito de qualidade do SGA. 
- A questão que obteve a maior frequiência de resposta 4 (relativa à métrica "muitas vezes") foi a questão Q14, com 17 respostas. Essa questão refere-se ao quesito Formato, perguntando especificamente se o usuário considera que as informações resultantes do sistema são apresentadas em um formato útil. A freqüência obtida nesta questão indica que 53\% dos usuários manifestaram que muitas vezes o formato dos resultados do Sistema SGA gera satisfação.

\subsection{Análise dos Quesitos da Satisfação do Usuário}

A Tabela 2 apresenta as porcentagens referentes às respostas dadas pelos usuários quanto à satisfação do usuário relativa a cada um dos quesitos que compõem a satisfação do usuário. Com base nessa tabela, serão analisados os resultados obtidos para os quesitos, a seguir.

Com base nos valores mostrados na Tabela 2 e nos parâmetros assumidos para avaliação da Pergunta 1 da pesquisa, pode-se destacar aos seguintes resultados:

- Quanto ao Conteúdo do Sistema. Os resultados sugerem que os usuários estão muito satisfeitos com o sistema, no tocante ao quesito Conteúdo do Sistema. Isso porque a porcentagem das respostas 5 ("sempre ou quase sempre"), juntamente com a das respostas 4 ("muitas vezes"), somou 85,93\%. Adicionalmente, nenhum usuário anotou a resposta 1 (nunca ou quase nunca) e a porcentagem obtida somando-se as respostas 2 e 3 foi pequena, apenas $14,1 \%$.

Tabela 2. Porcentagem das respostas para cada quesito

\begin{tabular}{|l|l|l|l|l|l|}
\hline & \multicolumn{1}{|c|}{$\begin{array}{c}1 \\
\text { Nunca ou } \\
\text { quase nunca }\end{array}$} & $\begin{array}{c}\text { Algumas } \\
\text { vezes }\end{array}$ & $\begin{array}{c}\text { Metade das } \\
\text { vezes }\end{array}$ & $\begin{array}{c}\text { Muitas } \\
\text { vezes }\end{array}$ & $\begin{array}{c}\text { Sempre ou } \\
\text { quase sempre }\end{array}$ \\
\hline Conteúdo do Sistema & $0 \%$ & $6,25 \%$ & $7,85 \%$ & $48,43 \%$ & $37,35 \%$ \\
\hline Exatidão & 1,56 & 4,68 & 7,81 & 39 & 46,87 \\
\hline Segurança & 6,25 & 7,81 & 9,37 & 29,68 & 46,87 \\
\hline Formato & 0 & 3,12 & 12,5 & 50 & 34,37 \\
\hline Facilidade de Uso & 0 & 4,68 & 12,5 & 25 & 42,18 \\
\hline Pontualidade da Informação & 0 & 3,12 & 9,37 & 48,43 & 39,06 \\
\hline Velocidade do Sistema & 0 & 9,73 & 20,31 & 43,75 & 26,56 \\
\hline Flexibilidade & 14,06 & 18,75 & 17,18 & 26,56 & 23,43 \\
\hline Atratividade & 14,06 & 14,06 & 10,93 & 32,81 & 28,12 \\
\hline Satisfação Geral & 0 & 4,65 & 6,25 & 45,31 & 43,71 \\
\hline
\end{tabular}

- Quanto à Exatidão das Informações geradas pelo Sistema. Os resultados sugerem que os usuários estão muito satisfeitos com o sistema, no que se refere ao quesito Exatidão, uma vez que a soma das porcentagens das respostas 5 ("sempre ou quase sempre") e 4 ("muitas vezes") foi 85,87\%. Além disso, a soma das respostas negativas, incluindo os valores obtidos para as respostas 1,2 e 3 foi apenas $14 \%$.

- Quanto à Segurança do Sistema. Os resultados sugerem que os usuários estão satisfeitos, porém não muito satisfeitos com o sistema, considerando-se o quesito Segurança. Pode-se assumir tal interpretação, pois a soma das porcentagens obtidas para as respostas 5 ("sempre ou quase sempre") e 4 ("muitas vezes") foi $76,55 \%$. Destaca-se também que a soma das demais respostas obtidas equivale a 
23,43\%, o que é um indicativo para um menor nível de satisfação dos usuários com aspectos de segurança do sistema.

- Quanto ao Formato das Informações e Resultados gerados pelo Sistema. Os resultados sugerem que os usuários estão muito satisfeitos com o sistema, no tocante ao quesito Formato. Isso porque a porcentagem das respostas 5 ("sempre ou quase sempre"), juntamente com a das respostas 4 ("muitas vezes"), somou $84,37 \%$. Adicionalmente, nenhum usuário anotou a resposta 1 (nunca ou quase nunca) e a porcentagem obtida somando-se as respostas 2 e 3 foi apenas 15,62 \%.

- Quanto à Facilidade de Uso do Sistema. Os resultados sugerem que os usuários estão satisfeitos com o sistema, porém não muito satisfeitos, no tocante ao quesito Facilidade de Uso. Isso porque a porcentagem das respostas 5 ("sempre ou quase sempre"), juntamente com a das respostas 4 ("muitas vezes"), somou 67,18\%. Adicionalmente, nenhum usuário anotou a resposta 1 (nunca ou quase nunca) e a porcentagem obtida somando-se as respostas 2 e 3 foi $17,18 \%$.

- Quanto à Pontualidade da Informação gerada pelo Sistema. Os resultados sugerem que os usuários estão muito satisfeitos com o sistema, no tocante ao quesito Pontualidade da Informação. Isso porque a porcentagem das respostas 5 ("sempre ou quase sempre"), juntamente com a das respostas 4 ("muitas vezes"), somou $87,49 \%$. Adicionalmente, nenhum usuário anotou a resposta 1 (nunca ou quase nunca) e a porcentagem obtida somando-se as respostas 2 e 3 foi 12,49\%.

- Quanto à Velocidade do Sistema. Os resultados sugerem que os usuários estão satisfeitos com o sistema, porém não muito satisfeitos, no tocante ao quesito Velocidade. Isso porque a porcentagem das respostas 5 ("sempre ou quase sempre"), juntamente com a das respostas 4 ("muitas vezes"), somou $70 \%$. Adicionalmente, nenhum usuário anotou a resposta 1 (nunca ou quase nunca) e a porcentagem obtida somando-se as respostas 2 e 3 foi $30 \%$.

- Quanto à Flexibilidade do Sistema. Os resultados sugerem que nível de satisfação dos usuários está no limite entre satisfação e insatisfação, no que se refere à Flexibilidade, uma vez que a soma das porcentagem das respostas 5 ("sempre ou quase sempre") e 4 ("muitas vezes") foi 49,99\%. Além disso, a soma das respostas obtidas para os valores 1,2 e 3 foi $50 \%$, o que é significativamente expressivo.

- Quanto à Atratividade do Sistema. Os resultados sugerem que os usuários estão satisfeitos com o sistema, porém não muito satisfeitos, no tocante à Atratividade. Isso porque a porcentagem das respostas 5 ("sempre ou quase sempre"), juntamente com a das respostas 4 ("muitas vezes") foi 60,93\%. Complementarmente, a soma das respostas obtidas para os valores 1,2 e 3 foi $40 \%$.

- Quanto à Satisfação Geral com o Sistema. Os resultados sugerem que os usuários estão muito satisfeitos com o sistema, no tocante ao quesito Satisfação Geral com o sistema. Isso porque a porcentagem das respostas 5 ("sempre ou quase sempre"), juntamente com a das respostas 4 ("muitas vezes"), somou $89 \%$. 
Adicionalmente, nenhum usuário anotou a resposta 1 (nunca ou quase nunca) e a porcentagem obtida somando-se as respostas 2 e 3 foi $10.9 \%$.

Em suma, os resultados obtidos através da análise dos quesitos que compõem a satisfação do usuário são:

- Os usuários mostraram-se muito satisfeitos com os quesitos: Conteúdo do Sistema; Exatidão das Informações geradas pelo Sistema; Formato das Informações e Resultados gerados pelo Sistema; Pontualidade da Informação gerada pelo Sistema; e Satisfação Geral.

- Os usuários mostraram-se satisfeitos, porém não chegando a sentir-se muito satisfeitos com os quesitos: Segurança do Sistema; Facilidade de Uso do Sistema; Velocidade do Sistema; e Atratividade do Sistema.

- Os usuários indicaram estar em um nível limítrofe entre satisfação e insatisfação quanto ao quesito Flexibilidade do Sistema.

- Os usuários não se manifestaram "muito insatisfeitos" em relação a nenhum dos quesitos considerados no estudo.

\subsection{Informações Adicionais}

A questão Q21 colheu informações adicionais que o usuário poderia fornecer sobre sua satisfação com o sistema SPG. Foram obtidas quinze respostas a essa questão, incluindo sugestões e críticas.

Entre as sugestões, destacam-se:

- O aspecto visual do sistema poderia ser mais interessante;

- Alteração de layout de relatório e inclusão de novos filtros nos relatórios;

- Atribuição de novas funções ao sistema, como folha de pagamento, cartão ponto, pedido de autorização de material;

- Treinamento para diminuir as dúvidas na utilização do sistema; Inclusão de mais informações nos relatórios, e novos relatórios;

- A localização do aluno por meio de outros índices, como telefone, RG ou CPF;

- A inclusão de um link com os correios para ajudar na localização dos endereços através do campo CEP.

As críticas apontadas foram:

- Algumas funções do sistema são difíceis de manusear, pois se o usuário selecionar uma opção errada, o resultado final pode ser comprometido; 
- As novas versões do sistema não levam em consideração a opinião do usuário, quanto às possíveis melhorias; Às vezes o sistema trava e gera mensagens de erro em inglês, sendo necessário contar com a ajuda do suporte para resolver o problema;

- Algumas vezes é necessário fechar a janela de chamada, e, ao reabri-la, verifica que o sistema não salvou as presenças já lançadas.

\subsection{Análise por Categorias de Usuários}

Conforme citado na seção 5.1, foi empregado o Teste Mann-Whitney [Pereira, 2004] para verificar se diferentes categorias de usuários do sistema expressavam diferentes níveis de satisfação em relação a um ou mais quesitos constantes do Modelo de Satisfação do Usuário. Esse teste possibilitou uma análise comparativa entre os resultados referentes a grupos distintos de usuários, considerando-se, para isso: (a) dois grupos de usuários, determinados com base nas funções por eles executadas, ou seja, funções de secretaria e funções de coordenação; (b) dois grupos de usuários, determinados com base no tempo de uso do software, ou seja, até um ano e acima de um ano.

Os resultados da análise feita através do Teste Mann-Whitney, assumindo-se um nível de significância de 0,05 , são apresentados na Tabela 3.

Tabela 3. Resultado do teste de Mann-Whitney

\begin{tabular}{|c|c|c|c|c|c|c|c|}
\hline \multirow{2}{*}{\multicolumn{2}{|c|}{$\begin{array}{l}\text { Questões } \\
\text { por quesito }\end{array}$}} & \multicolumn{3}{|c|}{ Função } & \multicolumn{3}{|c|}{ Tempo de uso } \\
\hline & & \multirow{2}{*}{\multicolumn{2}{|c|}{\begin{tabular}{|l|l|}
$\begin{array}{l}\text { Secre- } \\
\text { taria. }\end{array}$ & $\begin{array}{l}\text { Coor- } \\
\text { denação }\end{array}$ \\
\multicolumn{2}{|l}{ Medianas }
\end{tabular}}} & \multirow[b]{2}{*}{ pvalor } & $\begin{array}{l}\text { Até } \\
1 \text { ano }\end{array}$ & $\begin{array}{l}\text { Acima } \\
\text { de } 1 \text { ano }\end{array}$ & \multirow[b]{2}{*}{ pvalor } \\
\hline & & & & & Mediar & & \\
\hline \multirow{2}{*}{ Conteúdo } & Q1 & 4 & 4 & 0,97 & 4 & 4 & 0,50 \\
\hline & Q2 & 4 & 4 & 0,41 & 5 & 4 & 0,27 \\
\hline \multirow{2}{*}{ Exatidão } & Q3 & 4 & 5 & 0,35 & 5 & 4 & 0,14 \\
\hline & Q4 & 4 & 5 & 0,39 & 4 & 4 & 0,73 \\
\hline \multirow{2}{*}{ Segurança } & Q5 & 5 & 5 & 0,43 & 5 & 5 & 0,62 \\
\hline & Q6 & 5 & 4 & 0,82 & 4 & 4 & 0,31 \\
\hline \multirow{2}{*}{ Formato } & Q7 & 4 & 4 & 0,68 & 4 & 4 & 0,15 \\
\hline & Q8 & 4 & 4 & 0,88 & 4 & 4 & 0,73 \\
\hline \multirow{2}{*}{ Facilidade de uso } & Q9 & 4 & 4 & 0,60 & 4 & 4 & 0,71 \\
\hline & Q10 & 5 & 4 & 0,74 & 5 & 4 & 0,18 \\
\hline \multirow{2}{*}{$\begin{array}{l}\text { Pontualidade da } \\
\text { informação }\end{array}$} & Q11 & 4 & 4 & 1,00 & 4 & 4 & 0,79 \\
\hline & Q12 & 5 & 4 & $0,04 *$ & 4 & 4 & 0,34 \\
\hline \multirow{2}{*}{ Velocidade do sistema } & Q13 & 4 & 4 & 0,97 & 5 & 4 & 0,22 \\
\hline & Q14 & 4 & 4 & 0,85 & 4 & 4 & 0,24 \\
\hline \multirow{2}{*}{ Flexibilidade } & Q15 & 3 & 4 & 0,13 & 4 & 3 & 0,79 \\
\hline & Q16 & 3 & 3 & 0,91 & 4 & 3 & 0,47 \\
\hline \multirow{2}{*}{ Atratividade } & Q17 & 3 & 3 & 0,91 & 3 & 3 & 0,32 \\
\hline & Q18 & 4 & 4 & 0,30 & 4 & 4 & 0,45 \\
\hline \multirow{2}{*}{ Satisfação geral } & Q19 & 4 & 4 & 0,77 & 5 & 4 & $0,04 *$ \\
\hline & Q20 & 4 & 5 & 0,71 & 5 & 4 & 0,38 \\
\hline
\end{tabular}

$* \mathrm{p}<0,05 \rightarrow$ há diferença significativa. 
Os resultados mostrados na Tabela 2 levam às seguintes considerações:

- Quanto à Questão 12 (Q12). Essa questão refere-se à avaliação do quesito "pontualidade da informação" e indaga se o usuário tem a informação que precisa no prazo/tempo adequado. Os resultados mostraram que 58,82\% dos usuários que desempenham funções de secretaria responderam "sempre ou quase sempre", ao passo que apenas $20 \%$ dos usuários que desempenham funções de coordenação deram essa resposta. Tais resultados sugerem que o sistema atende mais prontamente às atividades mais estruturadas, que fazem parte do dia-a-dia da escola, fato que gera satisfação nos funcionários ligados a tais atividades. Porém, o sistema parece ser deficiente quanto ao atendimento de atividades de cunho gerencial, o que contribui para a insatisfação dos funcionários e professores que atuam na coordenação.

- Quanto à Questão 19 (Q19). Essa questão refere-se à avaliação do quesito "satisfação geral" e indaga se, de maneira geral, o usuário está satisfeito com o uso do sistema. Os resultados mostraram que a totalidade dos usuários (100\%) que têm até um ano de uso do sistema manifestou-se positivamente satisfeita, ou seja, 38,46\% dos usuários afirmaram estar "muitas vezes" satisfeitos e 61,54\% afirmou estar "sempre ou quase sempre" satisfeitos. Em contrapartida, entre os usuários que utilizam o sistema há mais de um ano, houve $21,06 \%$ que responderam estar apenas "algumas vezes" satisfeitos e 10,53\% afirmaram estar "metade das vezes" satisfeitos. Esse resultado sugere que os usuários com maior tempo de experiência com o sistema são mais críticos em relação às funcionalidades oferecidas pelo sistema, o que pode indicar a necessidade de atualizações periódicas e ajustes nos requisitos das diferentes classes de usuários.

\subsection{Análise de Confiabilidade}

Para avaliar a consistência e confiabilidade do estudo, foi utilizado o teste estatístico que mede o Coeficiente Alfa de Cronbach, que identifica a relação entre covariâncias e variâncias internas das medidas. De acordo com Pereira (2004), o teste é robusto o suficiente para tolerar escalas não-homogêneas e basear-se em correlações calculadas como razão de covariâncias e variâncias.

4.

Os valores obtidos através do Teste de Confiabilidade são mostrados na Tabela

Tabela 4 - Alfa de Cronbach para um indicador de Satisfação do Usuário

\begin{tabular}{|l|c|c|c|}
\hline Estatística & Média & Desvio Padrão & N de Variáveis \\
\hline por Escala & $\mathbf{3 , 9 9 3 8}$ & $\mathbf{1 , 0 4 5 0}$ & $(\mathbf{1 0})$ \\
\hline \multicolumn{3}{|c|}{ Coeficiente Confiável } \\
\hline \multicolumn{3}{|c|}{ N de Casos $=32$} \\
\hline \multicolumn{3}{|c|}{ N de Itens $=20$} \\
\hline \multicolumn{3}{|c|}{ Alfa Geral $=\mathbf{0 , 8 6 4 6}$} \\
\hline
\end{tabular}

Os números obtidos para o coeficiente Alfa foram interpretados como indicadores da eficiência do Questionário de Avaliação da Satisfação do Usuário em avaliar os atributos de satisfação do usuário. O Alfa geral do estudo foi de 0,8646 , o que 
pode ser considerado um resultado bastante satisfatório, uma vez que, para um valor máximo de 1, obteve-se um Alfa de 0,8646. Isso significa que o estudo, de uma forma geral, teve consistência e que os resultados obtidos podem ser considerados confiáveis.

\section{Conclusão}

Este trabalho abordou a satisfação do usuário de sistemas de software, visando atender a dois objetivos principais: propor um modelo de avaliação da satisfação do usuário; e discutir um estudo exploratório, realizado junto a usuários de um Sistema de Gestão Acadêmica, baseado no modelo proposto.

O trabalho buscou contribuir para o tema enfocado, uma vez que o número de pesquisas sobre esse assunto é muito reduzido, principalmente no Brasil. Neste sentido, o Modelo de Satisfação do Usuário proposto poderá ser útil para futuras pesquisas e avaliações. Por sua vez, o estudo empírico realizado poderá servir de base para a condução de novas pesquisas que venham a ser realizadas.

Considerando-se os principais estudos existentes sobre satisfação do usuário, o trabalho ora relatado representa um avanço, uma vez que propôs um Modelo de Satisfação do Usuário simples e claro, com 21 questões, que demonstrou ser viável de ser utilizado, na prática, para a avaliação de sistemas de software reais, envolvendo usuários reais.

É importante destacar que os resultados obtidos através da pesquisa são representativos para o Sistema SGA, considerando-se sua utilização pelas unidades da Escola, que participaram da pesquisa. Neste sentido, a avaliação realizada apontou aspectos do Sistema SGA que precisam ser melhorados, com vistas a se atender mais amplamente as necessidades e expectativas das diferentes categorias de usuários do sistema considerado.

Finalmente, cabe enfatizar a necessidade de trabalhos futuros, que contribuam para refinar, ajustar e validar o Modelo e o Processo de Execução de estudos empíricos similares.

\section{Referências}

Abdnnour, S.F., Chaparro, B.S. and Farmer, S.M. (2005) "Using the End-User Computing Satisfaction (EUCS) Instrument to Measure Satisfaction with a Web Site”, Decision Sciences, Volume 36, Number 2, p. 341-364.

Abran, A., Khelif, A., Suryn, W. and Seffah, A. (2003) Consolidating the ISO Usability Models. Technical Report, Concordia University, Montreal, Canadá.

Barner, M.E. A. (2006) Comparative Usability and End-User Satisfaction Analysis of two Geographic Information System (GIS) Applications. Technical Report, Graduate School of Engineering and Management, Air Force Institute of Technology, Ohio, USA. 
Chin, W. and Lee, M.K. (2000) "A Proposed Model and Measurement Instrument for the Formation of IS Satisfaction: The Case of End-User Computing Satisfaction", International Conference on Information Systems, Brisbane, Australia, p. 553-563.

DeLone, W.H. and McLean, E.R. (1992) "Information Systems Success: The Quest for the Dependent Variables", Information Systems Research, Volume 3, Number 1, p. 60-95.

DeLone, W.H. and McLean, E.R. (2002) "Information System Success Revisited", Proceedings of the $35^{\text {th }}$ Hawaiian International Conference on Systems Sciences, Big Island, Hawaii, p. 238-249.

DeLone, W.H. and McLean, E.R. (2003) "The DeLone and McLean Model of Information System Success: A Ten-Year Update", Journal of Management Information Systems, Volume. 19, Number 4, p. 9-30.

Doll, W.J. and Torkzadeh, G. (1998) "The Measurement of End-User Computing Satisfaction”, MIS Quarterly, Volume 12, Number 2, p. 259-274.

Iivari, J. (2005) "An Empirical Test of the DeLone-McLean Model of Information System Success", The DATA BASE for Advances in Information Systems, Volume 36, Number 2, p. 8-27.

Ives, B., Olson, M. and Baroudi, J. (1993) "The Measurement of User Information Satisfaction", Communications of the ACM, Volume 26, Number 10, p. 785-793.

Levine, D.M., Berenson, M.L. and Stephan, D. (2005) Estatística: Teoria e Aplicações, 3 ed., Rio de Janeiro: LTC - Livros Técnicos e Científicos.

Pereira, J.C. (2004) Análise de Dados Qualitativos. 3. ed., São Paulo: Editora da Universidade de São Paulo.

Perini, J.C. (2008) Um Estudo sobre a Satisfação do Usuário de Sistemas de Software. Dissertação de Mestrado, Programa de Pós-Graduação em Ciência da Computação, Universidade Metodista de Piracicaba, SP.

Sommerville, I. (2007) Engenharia de Software. 8 ed., São Paulo, Pearson.

SPSS (2007) Statistical Package for de Social Sciences. Acessado em 10/11/2007. Disponível em: http://www.spss.com/spss/.

Travassos, G.H., Gurov, D. and Amaral, E.A. (2002) Introdução à Engenharia de Software Experimental. Relatório Técnico ES-590/02, Programa de Engenharia de Sistemas e Computação, COPPE UFRJ.

Wohlin, C. et al. (2000) Experimentation in Software Engineering: an Introduction. Kluwer Academic Publishers, USA.

Zviran, M., Gleser, C. and Avni, I. (2006) "User Satisfaction from Commercial Web Sites: The Effect of Design and Use", Information \& Management, Volume 43, Number 2, p. 157-178. 